\title{
Extra-haematological manifestations related to human parvovirus B19 infection: retrospective study in 25 adults
}

Marion Dollat ${ }^{1}$, Benjamin Chaigne ${ }^{1}$, Grégoire Cormier ${ }^{2}$, Nathalie Costedoat-Chalumeau ${ }^{1}$, François Lifermann ${ }^{3}$, Alban Deroux ${ }^{4}$, Emilie Berthoux ${ }^{5}$, Emmanuelle Dernis ${ }^{6}$, Thomas Sené ${ }^{7}$, Gilles Blaison ${ }^{8}$, Olivier Lambotte ${ }^{9}$, Benjamin Terrier ${ }^{1}$, Jérémie Sellam ${ }^{10}$, Luc De Saint-Martin ${ }^{11}$, Laurent Chiche ${ }^{12}$, Nicolas Dupin $^{13}$ and Luc Mouthon ${ }^{1,14^{*}}$

\begin{abstract}
Background: To describe extra-haematological manifestations associated with human parvovirus B19 (HPV-B19) infection.

Methods: We conducted a nationwide multicentre study to retrospectively describe the characteristics and outcome of extra-haematological manifestations in French adults.

Results: Data from 25 patients followed from 2001 to 2016 were analysed. Median age was 37.9 years (range: 22.783.4), with a female predominance (sex ratio: 4/1). Only 3 patients had an underlying predisposing condition (hemoglobinopathy or pregnancy). The most common manifestations were joint (80\%) and skin (60\%) involvement. Four patients (16\%) had renal involvement (endocapillary proliferative or membranoproliferative glomerulonephritis, focal segmental glomerulosclerosis). Three patients (12\%) had peripheral nervous system involvement (mononeuritis, mononeuritis multiplex, Guillain-Barré syndrome) and 2 (8\%) presented muscle involvement. Other manifestations included hemophagocytic lymphohistiocytosis $(n=1)$, myopericarditis and pleural effusion $(n=1)$, and lymphadenopathy and splenomegaly mimicking lymphoma with spleen infarcts $(n=1)$. Immunological abnormalities were frequent (56.5\%). At 6 months, all patients were alive, and $54.2 \%$ were in complete remission. In 2 patients, joint involvement evolved into rheumatoid arthritis. Six patients (24\%) received intravenous immunoglobulin (IVIg), with a good response in the 3 patients with peripheral nervous system involvement.

Conclusions: HPV-B19 infection should be considered in a wide range of clinical manifestations. Although the prognosis is good, IVlg therapy should be discussed in patients with peripheral nerve involvement. However, its efficacy should be further investigated in prospective studies.
\end{abstract}

Keywords: Human parvovirus B19, Arthritis, Vasculitis, Glomerulonephritis, Peripheral neuropathy, Intravenous immunoglobulin, lupus

\footnotetext{
* Correspondence: luc.mouthon@aphp.fr

${ }^{1}$ Service de Médecine Interne, Centre de Référence Maladies Systémiques

Autoimmunes Rares d'lle de France, Hôpital Cochin, Assistance

Publique-Hôpitaux de Paris (AP-HP), Université Paris Descartes, Paris, France

${ }^{14}$ Service de médecine interne, Hôpital Cochin, 27, rue du faubourg

Saint-Jacques, 75679 Paris Cedex 14, France

Full list of author information is available at the end of the article
}

(c) The Author(s). 2018 Open Access This article is distributed under the terms of the Creative Commons Attribution 4.0 International License (http://creativecommons.org/licenses/by/4.0/), which permits unrestricted use, distribution, and reproduction in any medium, provided you give appropriate credit to the original author(s) and the source, provide a link to the Creative Commons license, and indicate if changes were made. The Creative Commons Public Domain Dedication waiver (http://creativecommons.org/publicdomain/zero/1.0/) applies to the data made available in this article, unless otherwise stated. 


\section{Background}

Human parvovirus B19 (HPV-B19) is a small DNA virus discovered in 1974 in the serum of healthy blood donors [1]. Primary infection is often asymptomatic [2]. Its pathogenic role was first reported in patients with sickle cell disease who developed aplastic crisis. It was then recognized as a causative agent of erythema infectiosum, hydrops fetalis and fetal deaths, and pure red cell aplasia (PRCA) in immunocompromised patients [3]. In young adults, HPV-B19 infection is also associated with joint manifestations [2, 4-10].

HPV-B19-related extra-haematological manifestations have been described, including glomerulonephritis, myositis, myocarditis, vasculitis and nervous system involvement, [11-17]. Furthermore, HPV-B19 infection can favour the development of auto-immune manifestations [18]. Limited data have been reported on the outcome and management of extra-haematological manifestations of HPV-B19 infection.

Intravenous immunoglobulin (IVIg) preparations have been proposed to treat persisting infection in immunocompromised patients [19]. Although their efficacy is established for treating HPV-B19 PRCA, data on IVIg treatment for extra-hematological manifestations are scarce and rely on case reports and small series [20-23]. In the present work, we aimed to better characterize the spectrum of extra-haematological manifestations related to HPV-B19 infection in adult patients, with a particular focus on treatment and outcome.

\section{Methods}

\section{Patients}

We conducted a nationwide multicenter study involving members of the Société Nationale Française de Médecine Interne (SNFMI) and the Club Rhumatismes et Inflammations (CRI). Practitioners who had cared for patients with extra-hematological manifestations attributed to HPV-B19 infection between January 2001 and March 2016 were invited to anonymously report cases. The 1500 members of the SNMFI were contacted through the SNFMI website (http://www.snfmi.org) and mailing list and the 2500 members of the CRI were contacted through the CRI website (http://www.cri-net.com) and mailing list. Patients over 18 years old with at least one extra-haematological manifestation associated with HPV-B19 infection were included. HPV-B19 infection diagnosis was based on positive anti-HPV-B19 IgM serology and/or detection of HPV-B19 DNA by polymerase chain reaction (PCR) in peripheral blood and/or bone marrow or another tissue. PCR amplification could be quantitative, semi-quantitative, or qualitative. Patients with isolated hematological manifestations were excluded.

\section{Patient data}

A standardized form was used to collect data on age; sex; underlying conditions; HPV-B19 infection diagnosis and manifestations; laboratory data: C-reactive protein (CRP) level, creatininemia, serum transaminase level, creatine phosphokinase level, antinuclear antibodies (Abs) (ANA), anti-double stranded DNA (anti-dsDNA) Abs, anti-extractable nuclear antigen (anti-ENA) Abs, lupus anticoagulant; anti-phospholipid Abs, anticardiolipin Abs, complement proteins $\mathrm{C} 3$ and $\mathrm{C} 4$, haemolytic complement activity, rheumatoid factor, anti-citrulli nated Abs (ACPA), anti-neutrophil cytoplasmic Abs (ANCA), and cryoglobulinemia; treatment; and outcome. Day 1 was considered the day of the first clinical symptom. Outcomes were determined at 1, 6, and 12 months, when available.

\section{Ethics, consent and permissions}

This study was conducted in compliance with the protocol of Good Clinical Practices and Declaration of Helsinki principles. In accordance with French law (Loi de Santé publique 2004 - Loi $\mathrm{n}^{\circ}$ 2004-806 du 9 août 2004), the need for consent was deemed unnecessary and formal approval from an ethical committee was not required for this study.

\section{Results}

In total, 15 practitioners answered our call for clinical cases and 25 patients with extra-haematological manifestations related to HPV-B19 infection were included. Their characteristics are in Table 1. Eighteen (72\%) were younger than 40 years. The female-to-male ratio was $4 / 1$. Only 4 patients had a significant underlying condition: 2 had hemoglobinopathy (patient 7: alpha-thalassemia, patient 17: sickle cell disease), one had a history of cutaneous lupus (patient 12), and one was pregnant (23 weeks, patient 4 ). Median time to diagnosis was 13 days (range: 0-197). In 7 patients (28\%), the occurrence of extra-haematological manifestations was preceded by an influenza-like illness. Three patients (12\%) had a contact with a child with erythema infectiosum. Inflammatory syndrome, when present (19/24 cases, 79\%), was moderate (median CRP level: $19 \mathrm{mg} / \mathrm{L}$, range: $0-132)$. The diagnosis of HPV-B19 infection was based on positive serology (IgM) in 17 patients (68\%), positive blood PCR in $2(8 \%)$, or both in $6(24 \%)$. In one patient, a bone-marrow biopsy was performed; PCR findings were positive for HPV-B19 DNA.

\section{Clinical manifestations}

The most common extra-haematological manifestations were joint and skin involvement. Common manifestations were also kidney and PNS involvement (Table 2). Less common manifestations included myopericarditis, muscle involvement and vasculitis. 
Dollat et al. BMC Infectious Diseases (2018) 18:302

Page 3 of 10

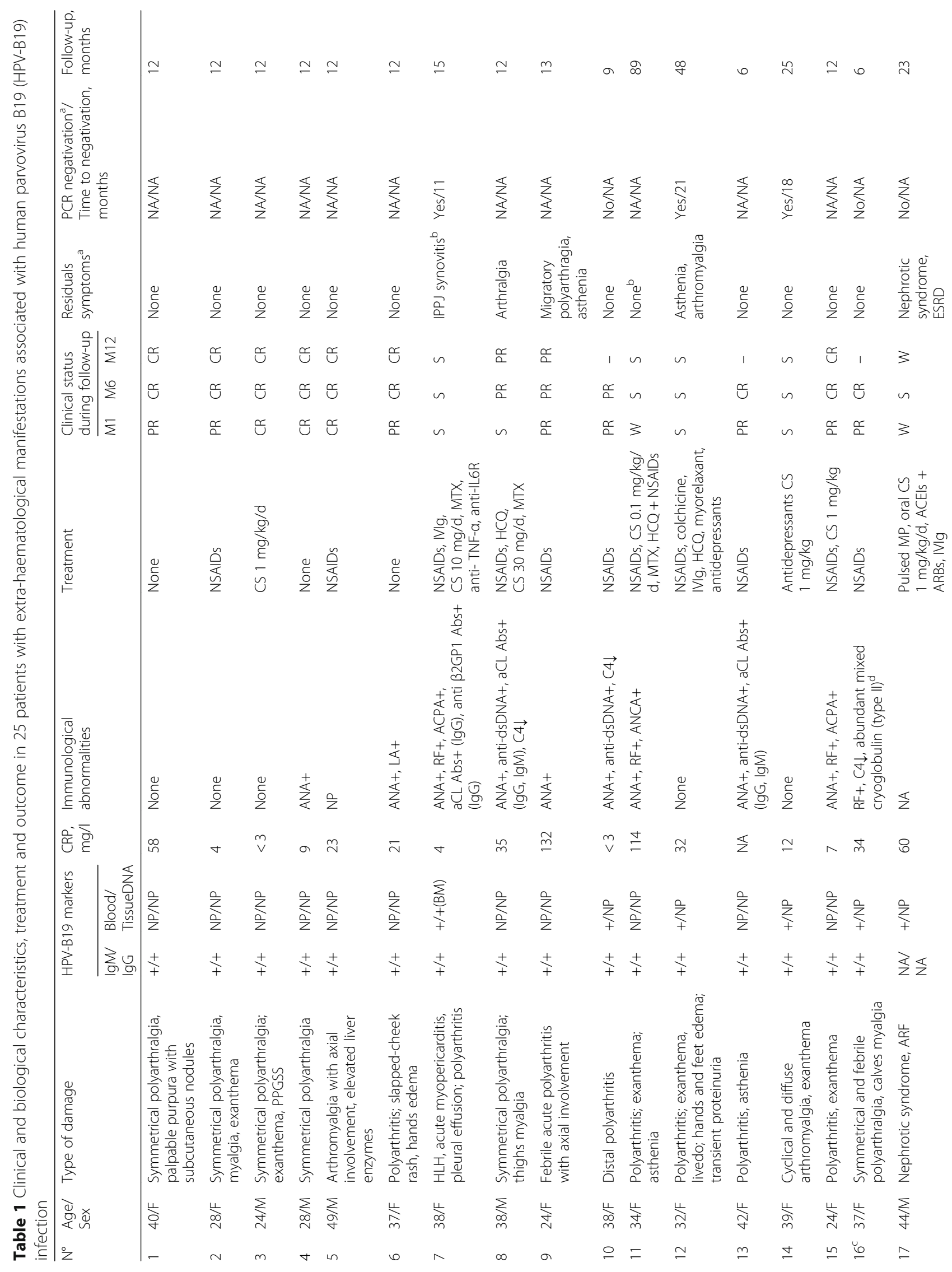


Dollat et al. BMC Infectious Diseases (2018) 18:302

Page 4 of 10

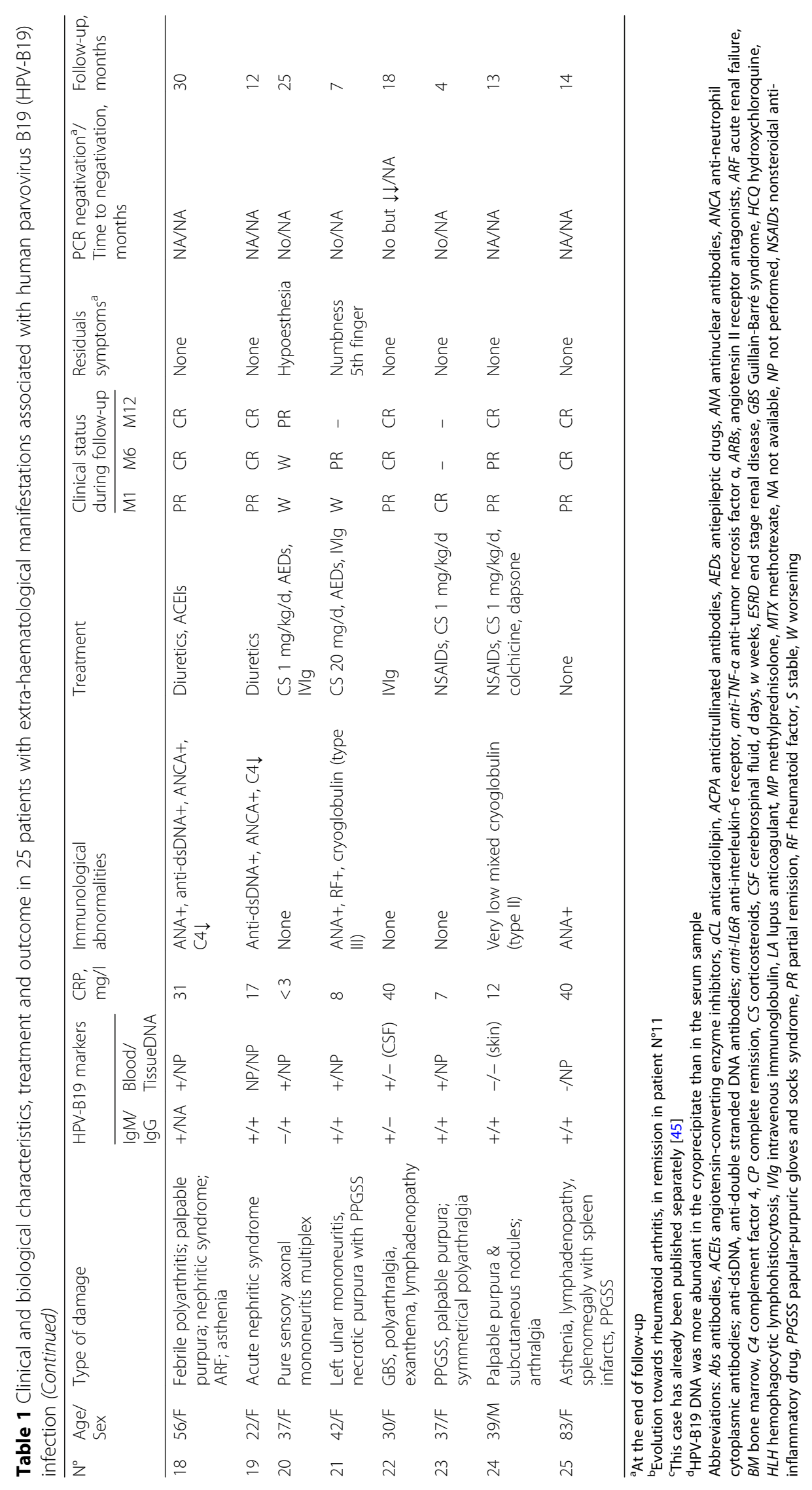


Table 2 Clinical characteristics in 25 patients with extrahaematological manifestations associated with human parvovirus B19 infection

\begin{tabular}{ll}
\hline Age, years, median (range) & $37.9(22.7-83.4)$ \\
Female sex & $20(80)$ \\
Joint involvement & $20(80)$ \\
Symmetrical polyarthralgia & $11(44)$ \\
Arthritis & $9(36)$ \\
Skin involvement & $15(60)$ \\
Exanthema & $8(32)$ \\
Palpable purpura & $5(20)$ \\
PPGSS & $4(16)$ \\
Periflexural pattern & $2(8)$ \\
Other & $4(16)$ \\
Renal involvement & $4(16)$ \\
Endocapillary proliferative GN & $1(4)$ \\
Membranoproliferative GN + FSGS & $1(4)$ \\
Undetermined & $2(8)$ \\
Neurological involvement & $3(12)$ \\
Mononeuritis & $1(4)$ \\
Mononeuritis multiplex & $1(4)$ \\
Guillain-Barré syndrome & $1(4)$ \\
Other & $11(44)$ \\
Myalgia & $5(20)$ \\
Asthenia & $3(12)$ \\
Mevated liver enzymes & $1(4)$ \\
Spleen infarcts & $1(4)$ \\
\hline Data aren (\%) unless ndicated & $1(4)$ \\
M &
\end{tabular}

Data are $\mathrm{n}(\%)$ unless indicated

Abbreviations: FSGS focal segmental glomerulosclerosis, GN

glomerulonephritis, PPGSS papular-purpuric gloves and socks syndrome

\section{Joint involvement}

Twenty patients had joint manifestations; 11 (44\%) presented symmetrical polyarthralgia involving peripheral joints. Nine (36\%) patients had synovitis; 3 (12\%) had acute febrile polyarthritis. Wrists $(n=14,56 \%)$, ankles $(n=14,56 \%)$, knees $(n=14,56 \%)$ and hands $(n=11$, $44 \%)$, including proximal and distal inter-phalangeal joints, were more often involved, whereas elbows $(n=7$, $28 \%)$, shoulders $(n=6,24 \%)$, feet $(n=2,8 \%)$ and hips $(n$ $=1,4 \%$ ) concerned less patients. Axial involvement was identified in 2 patients $(8 \%)$.

\section{Skin involvement}

Fifteen patients had skin manifestations. Skin lesions included erythema $(n=9,36 \%)$, palpable purpura $(n=5$, $20 \%)$, papules $(n=2,8 \%)$, and nodules $(n=2,8 \%)$, and were frequently associated. Five $(20 \%)$ patients reported pruritus. Exanthema affected legs $(n=4,16 \%)$, trunk ( $n=3,12 \%)$, arms $(n=2,8 \%)$, and was generalized in one patient (Fig. 1$)$.
The face was involved in one woman, with the "slapped cheek" sign. Four patients presented with papulo-purpuric gloves-and-socks syndrome (PPGSS) (Fig. 1). A periflexural involvement was reported in 2 patients (8\%) (Fig. 1), with petechial purpura in a baboon syndrome-like distribution in one. Subcutaneous nodules were identified in 2 patients (8\%), localized on thighs or feet and forearms. Oedema was detected in 3 patients (12\%), involving hands, feet, or both. One patient presented livedo localized to the lower limbs. Skin biopsies performed in 4 patients (16\%) revealed leukocytoclastic vasculitis in 2, fibrinoid necrosis and capillary thrombosis with immunoglobulins and complement deposits in one and Sweet's syndrome in one.

\section{Renal involvement}

Four patients had renal involvement. Transient moderate proteinuria was found in one patient. Two patients presented generalized oedema and acute nephritic syndrome and one had nephrotic syndrome with acute renal failure. Kidney biopsy was performed in 2 patients, revealing a focal and segmental endocapillary proliferative glomerulonephritis (GN) with C3 and kappa light chain deposits in the first patient and membranoproliferative GN with focal segmental glomerulosclerosis lesions in the other. When performed $(n=1)$, immunohistochemical study was negative for HPV-B19.

\section{Neurological involvement}

Three patients showed neurological involvement. One patient presented mononeuritis multiplex with progressive sensory disorders. Electrophysiological examinations revealed a distal and pure sensory involvement predominantly affecting small fibres. One patient complained of painful paresthesia and dysesthesia in the left ulnar nerve territory, with electrophysiological study suggesting an isolated ulnar mononeuritis with sensory-motor disorders. In one patient, clinical and electrophysiological examination led to the diagnosis of Guillain-Barré syndrome, restricted to lower limbs. In this patient, PCR findings for HPV-B19 DNA in cerebrospinal fluid were negative.

\section{Other}

Two patients had lower-limb myalgia with inflammatory muscular infiltration revealed by MRI but normal serum creatine phosphokinase level. One patient had abundant mixed cryoglobulin. Three patients (12\%) had transient and moderate cytolytic hepatitis. One patient initially presented an acute severe clinical picture combining hemophagocytic lymphohistiocytosis, pleural effusion, and myopericarditis. One patient had febrile lymphadenopathy and splenomegaly mimicking lymphoma with multiple spleen infarcts: inguinal lymph node biopsy 


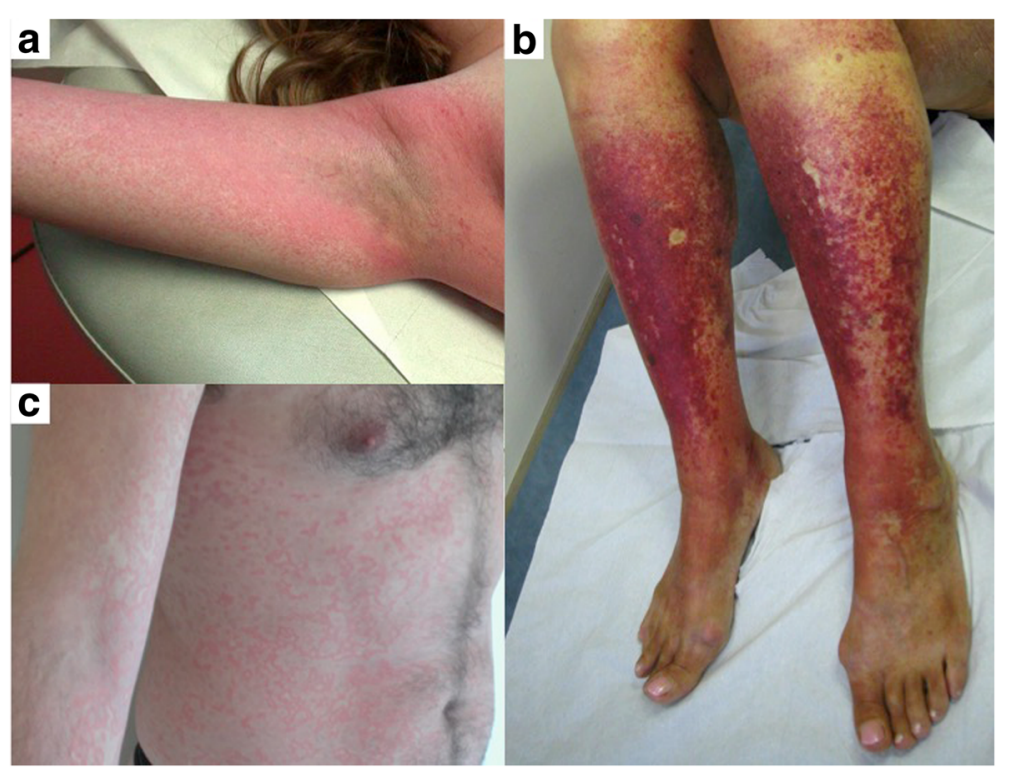

Fig. 1 Skin manifestations related to human parvovirus B19 infection. Panel a: periflexural purpuric exanthema. Panel b: purpuric lesions of the lower limbs in a patient with the gloves and socks pattern. Pnael c: reticulate and annular exanthema of the trunk

showed adenitis. Four other patients also showed lymphadenopathy.

Of note, extra-haematological manifestations were associated with haematological biological disorders in 11 patients $(44 \%)$ and included anemia $(n=8,32 \%)$, lymphocytopenia $(n=4,16 \%)$, thrombocytopenia $(n=2,8 \%)$, and pancytopenia $(n=1,4 \%)$. Anemia was non-regenerative and moderate in 6 patients. In these patients, median [interquartile range] reticulocyte count was 65,000 [36000-167,500] cell/ $\mathrm{mm}^{3}$. Among the 3 patients who underwent bone-marrow aspiration, none had PRCA.

\section{Immunological abnormalities}

Immunological tests were available for 23 (92\%) patients, with abnormalities detected in 13 (56.5\%). ANA were present in 9 patients (39.1\%; median [interquartile range] titre 80 [80-160]), with a speckled fluorescence; 5 (21.7\%) had anti-dsDNA Abs (median [interquartile range] titre 99 [48-187]). None had anti-ENA Abs. Low C4 fraction level was observed in 7 of 18 patients (38.9\%) (median [interquartile range] level 0.12 [0.0950.14] g/L) including 4 with anti-dsDNA Abs. C3 fraction level was available and normal in 17 patients (100\%). Anti-phospholipid Abs were found in 4 of 11 patients (36.4\%): anti-cardiolipin Abs (IgG, $n=3 ; \operatorname{IgM}, \mathrm{n}=2$ ), anti- $\beta 2$-glycoprotein1 Abs (IgG, $n=1$ ), or lupus anticoagulant $(n=1)$. Six of 17 patients $(35.3 \%)$ had rheumatoid factor, including 2 with ACPA. Three of 7 patients (42.9\%) had mixed cryoglobulinemia: type II (2 cases), or type III $(n=1)$. ANCA were present in 3 of 15 patients (20\%). In 5 of the 6 patients with repeated immunological tests, autoantibodies disappeared after 1 or
2 months. One patient had persistent anti-dsDNA Abs on ELISA 5 months after onset.

\section{Treatment and outcome}

After a median (range) follow-up of 12 (4-89) months, every patient was alive. Four patients (16\%) were in complete remission at 1 month, $13 / 24$ (54.2\%) at 6 months, and 12/20 (48\%) at 12 months (Table 3). Four patients $(16 \%)$ showed improvement without any treatment. Non-steroidal anti-inflammatory drugs (NSAIDs) and corticosteroids were the most frequently prescribed treatments, whereas 6 patients received IVIg (Table 3).

Table 3 Treatment and outcome in patients with extrahaematological manifestations associated with HPV-B19 infection $(n=25)$

\begin{tabular}{ll}
\hline Treatment $(n=25)$ & $4(16)$ \\
None & $12(48)$ \\
NSAIDs & $11(44)$ \\
Corticosteroids & $6(24)$ \\
IVIg & \\
Outcome & \\
At 6 months $(n=24)$ & $13(54.2)$ \\
$\quad$ Complete remission & $5(20.8)$ \\
Partial remission & \\
At 12 months ( $n=20)$ & $12(60)$ \\
$\quad$ Complete remission & $3(15)$ \\
Partial remission
\end{tabular}

Data are $\mathrm{n}(\%)$ unless indicated

Abbreviations: IVIg intravenous immunoglobulin, NSAIDs non-steroidal anti-inflammatory drugs 
Out of the 11 patients who received corticosteroids, 5 patients received corticosteroids before the diagnosis of HPV-B19 infection. In those 5 cases, corticosteroids were mostly empirically chosen due to the presence of joint involvement. Regarding the 6 other patients, corticosteroids were prescribed because of skin, neurological or kidney involvement. Remission or stabilisation was noted at 12 months in every patient who received corticosteroids except for one patient with nephrotic syndrome. Complete remission was noted in three patients.

Thirteen patients (52\%) with joint involvement received NSAIDs: complete remission was observed with this treatment alone in 6 patients. Corticosteroids were prescribed to 5 patients (20\%): 2 achieved complete response and one partial response. Two patients with joint involvement received IVIg, without efficacy (Table 4). Six patients showed persistent arthralgia or arthritis after 1 year of follow-up, notably 2 in whom rheumatoid arthritis (RA) developed.

Exanthema resolved spontaneously in all patients in 24 to $72 \mathrm{~h}$. Corticosteroids were used in every patient with cutaneous vasculitis or Sweet's syndrome and led to complete resolution in a few days or weeks except for one patient who required 9 months of treatment (patient 24).

The 2 patients with mononeuritis received corticosteroids with IVIg. IVIg was prescribed 15 days after corticosteroids in one and after 5 months in the other. Both patients showed mild neurological sequelae (Table 4). Guillain-Barré syndrome symptoms completely resolved after a single course of IVIg.
Finally, regarding renal involvement, end-stage renal disease (ESRD) developed in one patient (patient 17) despite monthly courses of IVIg. The patient with transient proteinuria did not show relapse and the 2 others recovered in 3 months.

PCR for HPV-B19 DNA was repeatedly performed during follow-up in 10 patients: 3 were negative for viremia, at 11 and 21 months in 2 patients who had received IVIg, and at 18 months in the third patient, who had only received corticosteroids.

\section{Discussion}

HPV-B19 is a common pathogen in humans and mainly affects children and young adults. Seroprevalence in developed countries is 40 to $60 \%$ in adults older than 20 years and reaches over $90 \%$ in older people [24]. In adults, primary infection is asymptomatic or follows a two-phase benign course: an early phase with fever and nonspecific influenza-like symptoms, and a secondary phase with erythema, arthralgia, and appearance of anti-HPV-B19 IgM $[2,25,26]$. Haematological disorders associated with HPV-B19 are well identified and commonly described [27, 28]. Conversely, extra-haematological manifestations have been reported less frequently, mainly in case reports or small series, focusing on a single manifestation. Of note, the present study confirms the female predominance of symptomatic infection and the occurrence between age 20 and 40 years in most cases $[4-7,9]$.

A few studies in adults have described symptoms and clinical characteristics of HPV-B19 infection [2, 4-10, 17]. Like these earlier studies, we found joint and

Table 4 Treatment regimen and outcome for 6 patients who received intravenous immunoglobulin for extra-haematological manifestations associated with HPV-B19 infection

\begin{tabular}{|c|c|c|c|c|c|c|}
\hline \multirow[t]{2}{*}{ Predominant involvement } & Patient 7 & Patient 12 & Patient 17 & Patient 20 & Patient 21 & Patient 22 \\
\hline & $\begin{array}{l}\text { Chronic } \\
\text { polyarthritis }\end{array}$ & $\begin{array}{l}\text { Chronic poly- } \\
\text { arthralgia }\end{array}$ & $\begin{array}{l}\text { Membrano-proliferative } \\
\text { GN + FSGS }\end{array}$ & $\begin{array}{l}\text { Mononeuritis } \\
\text { multiplex }\end{array}$ & Mononeuritis & $\begin{array}{l}\text { Guillain-Barré } \\
\text { syndrome }\end{array}$ \\
\hline \multicolumn{7}{|l|}{ Treatment regimen } \\
\hline IVlg courses, $n$ & 1 & 1 & 20 & 20 & 1 & 1 \\
\hline IVlg first dose, g/kg & 2 & 2 & 2 & 2 & 2 & 2 \\
\hline IVlg total dose, $\mathrm{g} / \mathrm{kg}$ & 2 & 2 & 36 & 37 & 2 & 2 \\
\hline Additional treatment & NSAIDs & NSAIDs & CS, ACEIs, ARBS & CS, AEDs & None & None \\
\hline \multicolumn{7}{|l|}{ Outcome } \\
\hline Clinical response M1 & Stable & Stable & Stable & Worse & Stable & Partial \\
\hline Clinical response M2 & Stable & Stable & Stable & Partial & Stable & Partial \\
\hline Clinical response M6 & Stable & Stable & Stable & Partial & Partial & Complete \\
\hline HPV-B19 PCR negativity & Yes & Yes & No & No & No & No \\
\hline $\begin{array}{l}\text { Time to PCR negativity, months after } \\
\text { diagnosis/1st course }\end{array}$ & $11 / 06$ & $21 / 12$ & - & - & - & - \\
\hline
\end{tabular}

Abbreviations: ACEls angiotensin-converting enzyme inhibitors, AEDs antiepileptic drugs, ARBs angiotensin II receptor antagonists, CS corticosteroids, FSGS focal segmental glomerulosclerosis, GN glomerulonephritis, IVIg intravenous immunoglobulin, $M$ month, NSAIDs non-steroidal anti-inflammatory drugs, $P C R$ polymerase chain reaction 
cutaneous manifestations to be common and had a favourable outcome in most cases, with good response to NSAIDs [2, 4-10]. However, in our patients, joint symptoms persisted 6 months after onset in $28 \%$ of patients versus 8 to $20 \%$ in previous series [2, 5, 6, 9]. In 2 of our patients, in whom rheumatoid factor was detected, RA was subsequently diagnosed. Although HPV-B19 infection preceding or mimicking RA has been reported [29], the presence of ACPA and joint destruction has not been described until now. Regarding cutaneous manifestations, our series is similar to previous series but highlights an association of Sweet's syndrome and HPV-B19 infection, only reported twice before [14, 30]. Atypical extra-haematological manifestations such as renal injury, neurological complications or myocarditis associated with HPV-B19 have been less described in previous series and represented $12 \%$ of our patients. In our series, $52 \%$ patients presented manifestations other than joint or cutaneous features (i.e., renal, neurological, muscular, hepatic, pleuro-pericardial or splenic involvement), which highlights the need to seek these complications in patients with HPV-B19 infection. Of note, the present study adds a fifth case of Guillain-Barré syndrome related to HPV-B19 infection (patient 22) [31].

In the present study, most patients had immunological abnormalities (65.2\%), which resolved in a few weeks. As for other viral infections, HPV-B19 infection can induce the production of various auto-Abs [26]. ANA and/or anti-dsDNA Abs were identified in more than $25 \%$ of patients in previous studies, versus 39 and $22 \%$, respectively, in our series $[9,32]$. Anti-phospholipid Abs were also frequently found, without clinical significance, in $14 \%$ of patients in one series, versus $36 \%$ in our study [9]. Low C4 level was previously reported in 32 to $44 \%$ of patients, which agrees with our results $(39 \%)[4,7,9]$. Thus, HPV-B19 infection may mimic both clinical and laboratory features of systemic lupus erythematosus (SLE), which justifies the need to screen for HPV-B19 infection when patients are referred for suspected SLE. Misdiagnosing systemic vasculitis is another difficulty: Hermann et al. found that $10 \%$ of patients with acute HPV-B19 infection (20\% in the present series) had ANCA [33]. Moreover, cases of necrotizing vasculitis associated with HPV-B19 infection and cases of SLE triggered by HPV-B19 have been reported [23, 34].

HPV-B19 infection in adults is usually associated with a good outcome and full recovery. However, some patients experience severe manifestations and/or prolonged symptoms. In these patients, immunomodulatory and anti-inflammatory agents such as corticosteroids and IVIg are needed. As in our series, corticosteroids are empirically the first-line treatment to be chosen. With its immunomodulatory and anti-inflammatory but also anti-infective properties, IVIg has been proposed to treat extra-haematological manifestations associated with HPV-B19 infection. Indeed, IVIg is only validated in PRCA in immunocompromised patients. Indeed, in 93\% patients reviewed by Crabol et al., haemoglobin level was normalized at a mean of $1.7 \pm 1.6$ months after the first IVIg course [20]. To date, use of IVIg to treat manifestations related to HPV-B19 infection has been evaluated in only one prospective uncontrolled study in the setting of dilated cardiomyopathy and reported in retrospective case studies and case reports [13, 21-23, 3543]. Although clinical improvement was reported in several cases, particularly for cardiac, vascular, and neurological involvement, relapses and/or sequelae frequently occurred. Moreover, discrepancies between clinical and virological responses were observed [13, 21-23, 35-43]. In the present study, 6 patients (24\%) received IVIg. Half of them, especially those with neurological manifestations, showed clinical improvement. As expected, patient 22, with Guillain-Barré syndrome, had a favourable outcome. Of note, both patients with peripheral neuropathy (patients 20 and 21) also experienced clinical impr ovement.

The present study has several limitations. Its retrospective design explains the missing data, including, for example, serial measurement of viral load. The number of cases is limited because of the low incidence of extra-haematological manifestations of HPV-B19 infection. Also, another possible explanation is the potential bias in B19 testing for uncommon clinical presentations related to B19 infections. Indeed B19 testing would always be considered in adults presenting with arthralgia and/or rash, whereas it would never or rarely be considered in patients presenting with kidney or neurological manifestations. Another limitation in our study is the variety of manifestations which precludes any statistical analysis to identify prognostic factors or to assess treatment efficacy. Finally, when assessing corticosteroids or IVIg efficacy, progressive spontaneous improvement cannot be ruled out.

\section{Conclusions}

In conclusion, our results confirm that HPV-B19 infection should be considered in the differential diagnosis assessment of a wide range of manifestations. Extra-haematolo gical manifestations associated with HPV-B19 infection usually have a favourable outcome with supportive treatment. Furthermore, severe injury can occur, especially with neurological involvement: in these rare cases, IVIg treatment could be discussed, although its efficacy remains to be documented. Hence, more prospective studies are needed to define the place of IVIg in the management of extra-haematological manifestations associated with HPV-B19 infection [44]. 


\section{Abbreviations}

Abs: Antibodies; ACPA: Anti-citrullinated Abs; ANA: Antinuclear Abs; ANCA: Anti-neutrophil cytoplasmic Abs; Anti-dsDNA: Anti-double stranded DNA; CRI: Club rhumatismes et inflammations; CRP: C-reactive protein; ESRD: End-stage renal disease; GN: Glomerulonephritis; HPV-B19: Human parvovirus B19; IVIg: Intravenous immunoglobulin; NSAIDs: Non-steroidal anti-inflammatory drugs; PCR: Polymerase chain reaction; PPGSS: Papulopurpuric gloves-and-socks syndrome; PRCA: Pure red cell aplasia; RA: Rheumatoid arthritis; SLE: Systemic lupus erythematosus; SNFMI: Société nationale Française de médecine interne

\section{Availability of data and materials}

Data and material are available upon request to the corresponding author.

\section{Authors' contributions}

$M D$, and $L M$ designed the study. MD, GC, NCC, FL, AD, EB, ED, TS, GB, OL, BT, $J S, L S M, L C, N D$, LM acquired data for the manuscript. MD, BC and LM wrote the manuscript. All authors reviewed and accepted the manuscript.

\section{Ethics approval and consent to participate}

This study was conducted in compliance with the protocol of Good Clinical Practices and Declaration of Helsinki principles. In accordance with French law (Loi de Santé publique 2004 - Loi n²004-806 du 9 août 2004), the need for consent was deemed unnecessary and formal approval from an ethical committee was not required for this study.

\section{Consent for publication}

Not applicable.

\section{Competing interests}

The authors declare that they have no competing interests.

\section{Publisher's Note}

Springer Nature remains neutral with regard to jurisdictional claims in published maps and institutional affiliations.

\section{Author details}

${ }^{1}$ Service de Médecine Interne, Centre de Référence Maladies Systémiques Autoimmunes Rares d'lle de France, Hôpital Cochin, Assistance Publique-Hôpitaux de Paris (AP-HP), Université Paris Descartes, Paris, France. ${ }^{2}$ Service de Rhumatologie, Centre Hospitalier Départemental Vendée, La Roche-sur-Yon, France. ${ }^{3}$ Service de Médecine Interne, Centre Hospitalier de Dax - Côte d'Argent, Dax, France. ${ }^{4}$ Service de Médecine Interne, Centre Hospitalier Universitaire Grenoble Alpes, Université Grenoble Alpes, Grenoble, France. ${ }^{5}$ Service de Médecine Interne, Centre Hospitalier Saint-Joseph Saint-Luc, Lyon, France. ${ }^{6}$ Service de Rhumatologie, Centre Hospitalier - Le Mans, Le Mans, France. ${ }^{7}$ Service de Médecine Interne, Hôpital Foch, Suresnes, France. ${ }^{8}$ Service de Médecine Interne, Centre Hospitalier Louis Pasteur, Colmar, France. '9Service de Médecine Interne et Immunologie, Hôpital Bicêtre, AP-HP, Université Paris-Sud, Le Kremlin-Bicêtre, France. ${ }^{10}$ Service de Rhumatologie, Hôpital Saint-Antoine, AP-HP, Université Pierre et Marie Curie, Paris, France. ${ }^{11}$ Service de Médecine Interne, Centre de Référence Maladies Systémiques Autoimmunes Rares Nord et Ouest, Centre Hospitalier Régional et Universitaire de Brest, Université de Bretagne Occidentale, Brest, France.

${ }^{12}$ Service de Médecine Interne, Hôpital Européen, Marseille, France. ${ }^{13}$ Service de Dermatologie, Hôpital Cochin, AP-HP, Université Paris Descartes, Paris, France. ${ }^{14}$ Service de médecine interne, Hôpital Cochin, 27, rue du faubourg Saint-Jacques, 75679 Paris Cedex 14, France.

\section{Received: 8 January 2018 Accepted: 29 June 2018}

Published online: 04 July 2018

\section{References}

1. Cossart YE, Field AM, Cant B, Widdows D. Parvovirus-like particles in human sera. Lancet. 1975 Jan 11;1(7898):72-3.

2. Woolf AD, Campion GV, Chishick A, Wise S, Cohen BJ, Klouda PT, et al. Clinical manifestations of human parvovirus B19 in adults. Arch Intern Med. 1989 May;149(5):1153-6.

3. Naides SJ. Rheumatic manifestations of parvovirus B19 infection. Rheum Dis Clin N Am. 1998 May;24(2):375-401.
4. Cathébras P, Robert F, Guglielminotti C, Bonnevial L, Rousset H. [primary parvovirus B19 infection in immunocompetent adults: clinical and biological manifestations. Retrospective study of 16 patients]. Rev. Med Int. 2000 Apr; 21(4):324-9.

5. Hayakawa H, Tara M, Niina K, Osame M. A clinical study of adult human parvovirus B19 infection. Intern Med Tokyo Jpn. 2002 Apr;41(4):295-9.

6. Kerr JR, Coyle PV, DeLeys RJ, Patterson CC. Follow-up study of clinical and immunological findings in patients presenting with acute parvovirus B19 infection. J Med Virol. 1996 Jan;48(1):68-75.

7. Oiwa H, Shimada T, Hashimoto M, Kawaguchi A, Ueda T, Sugiyama E, et al. Clinical findings in parvovirus B19 infection in 30 adult patients in Kyoto. Mod Rheumatol Jpn Rheum Assoc. 2011 Feb;21(1):24-31.

8. de OSA, Camacho LAB, Pereira AC de M, Faillace TF, Setubal S, do NJP. Clinical and epidemiological aspects of human parvovirus B19 infection in an urban area in Brazil (Niterói city area, state of Rio de Janeiro, Brazil). Mem Inst Oswaldo Cruz. 2002 Oct;97(7):965-70.

9. Parra D, Mekki Y, Durieu I, Broussolle C, Sève P. Clinical and biological manifestations in primary parvovirus B19 infection in immunocompetent adult: a retrospective study of 26 cases. Rev Med Int. 2014 May;35(5):289-96.

10. Waza K, Inoue K, Matsumura S. Symptoms associated with parvovirus B19 infection in adults: a pilot study. Intern Med Tokyo Jpn. 2007:46(24):1975-8.

11. Dennert R, Velthuis S, Westermann D, Donker D, Schalla S, van Suylen R-J, et al. Parvovirus-B19-associated fulminant myocarditis successfully treated with immunosuppressive and antiviral therapy. Antivir Ther. 2010;15(4):681-5.

12. Hillingsø JG, Jensen IP, Tom-Petersen L. Parvovirus B19 and acute hepatitis in adults. Lancet Lond Engl. 1998 Mar 28;351(9107):955-6.

13. Lenglet $T$, Haroche J, Schnuriger A, Maisonobe T, Viala K, Michel Y, et al. Mononeuropathy multiplex associated with acute parvovirus B19 infection: characteristics, treatment and outcome. J Neurol. 2011 Jul;258(7):1321-6.

14. Magro CM, Dawood MR, Crowson AN. The cutaneous manifestations of human parvovirus B19 infection. Hum Pathol. 2000 Apr;31(4):488-97.

15. Oliver ND, Millar A, Pendleton A, Oliver ND, Millar A, Pendleton A. A case report on parvovirus B19 associated myositis. Case Rep Rheumatol. 2012 Dec 10;2012(2012):e250537.

16. Taylor G, Drachenberg C, Faris-Young S. Renal involvement of human parvovirus B19 in an immunocompetent host. Clin Infect Dis Off Publ Infect Dis Soc Am. 2001 Jan;32(1):167-9.

17. Mage V, Lipsker D, Barbarot S, Bessis D, Chosidow O, Del Giudice P, et al. Different patterns of skin manifestations associated with parvovirus B19 primary infection in adults. J Am Acad Dermatol. 2014 Jul;71(1):62-9.

18. Posnett DN, Yarilin D. Amplification of autoimmune disease by infection. Arthritis Res Ther. 2005;7(2):74-84

19. Kurtzman G, Frickhofen N, Kimball J, Jenkins DW, Nienhuis AW, Young NS. Pure red-cell aplasia of 10 years' duration due to persistent parvovirus B19 infection and its cure with immunoglobulin therapy. N Engl J Med. 1989 Aug 24;321(8):519-23.

20. Crabol Y, Terrier B, Rozenberg F, Pestre V, Legendre C, Hermine O, et al. Intravenous immunoglobulin therapy for pure red cell aplasia related to human parvovirus b19 infection: a retrospective study of 10 patients and review of the literature. Clin Infect Dis Off Publ Infect Dis Soc Am. 2013 Apr; 56(7):968-77.

21. Kerr JR, Cunniffe VS, Kelleher P, Bernstein RM, Bruce IN. Successful intravenous immunoglobulin therapy in 3 cases of parvovirus B19associated chronic fatigue syndrome. Clin Infect Dis Off Publ Infect Dis Soc Am. 2003 May 1;36(9):e100-6.

22. Ogawa E, Otaguro S, Murata M, Kainuma M, Sawayama Y, Furusyo N, et al Intravenous immunoglobulin therapy for severe arthritis associated with human parvovirus B19 infection. J Infect Chemother Off J Jpn Soc Chemother. 2008 Oct;14(5):377-82.

23. Viguier M, Guillevin L, Laroche L. Treatment of parvovirus B19-associated polyarteritis nodosa with intravenous immune globulin. N Engl J Med. 2001 May 10;344(19):1481-2.

24. Kelly HA, Siebert D, Hammond R, Leydon J, Kiely P, Maskill W. The agespecific prevalence of human parvovirus immunity in Victoria, Australia compared with other parts of the world. Epidemiol Infect. 2000 Jun 124(3):449-57.

25. Kerr JR. Parvovirus B19 infection. Eur J Clin Microbiol Infect Dis. 1996;15(1):10-29.

26. Meyer O. Parvovirus B19 and autoimmune diseases. Jt Bone Spine Rev Rhum. 2003 Feb;70(1):6-11.

27. Brown KE, Young NS. Parvovirus B19 infection and hematopoiesis. Blood Rev. 1995 Sep;9(3):176-82 
28. Wolfromm A, Rodriguez C, Michel M, Habibi A, Audard V, Benayoun E, et al. Spectrum of adult parvovirus B19 infection according to the underlying predisposing condition and proposals for clinical practice. Br J Haematol. 2015 Jul;170(2):192-9.

29. Sève P, Ferry T, Charhon A, Calvet A, Broussolle C. [systemic manifestations of parvovirus B19 infections]. Rev. Med Int. 2004 Oct;25(10):740-51.

30. Fortna RR, Toporcer M, Elder DE, Junkins-Hopkins JM. A case of sweet syndrome with spleen and lymph node involvement preceded by parvovirus B19 infection, and a review of the literature on extracutaneous sweet syndrome. Am J Dermatopathol. 2010 Aug;32(6):621-7.

31. Barah F, Whiteside S, Batista S, Morris J. Neurological aspects of human parvovirus B19 infection: a systematic review. Rev Med Virol. 2014 May; 24(3):154-68.

32. Soloninka CA, Anderson MJ, Laskin CA. Anti-DNA and antilymphocyte antibodies during acute infection with human parvovirus B19. J Rheumatol. 1989 Jun; 16(6)::777-81.

33. Hermann J, Demel U, Stünzner D, Daghofer E, Tilz G, Graninger W. Clinical interpretation of antineutrophil cytoplasmic antibodies: parvovirus B19 infection as a pitfall. Ann Rheum Dis. 2005 Apr;64(4):641-3.

34. Trapani S, Ermini M, Falcini F. Human parvovirus B19 infection: its relationship with systemic lupus erythematosus. Semin Arthritis Rheum. 1999 Apr;28(5):319-25.

35. Attard L, Bonvicini F, Gelsomino F, Manfredi R, Cascavilla A, Viale P, et al. Paradoxical response to intravenous immunoglobulin in a case of parvovirus B19-associated chronic fatigue syndrome. J Clin Virol Off Publ Pan Am Soc Clin Virol. 2015 Jan;62:54-7.

36. Bonvicini F, Marinacci G, Pajno MC, Gallinella G, Musiani M, Zerbini M. Meningoencephalitis with persistent parvovirus B19 infection in an apparently healthy woman. Clin Infect Dis Off Publ Infect Dis Soc Am. 2008 Aug 1;47(3):385-7.

37. Dennert $R$, Velthuis $S$, Schalla $S$, Eurlings $L$, van Suylen $R-J$, van Paassen $P$, et al. Intravenous immunoglobulin therapy for patients with idiopathic cardiomyopathy and endomyocardial biopsy-proven high PVB19 viral load. Antivir Ther. 2010;15(2):193-201.

38. Guillaume MP, Hermanus N, Peretz A. Unusual localisation of chronic arthropathy in lumbar facet joints after parvovirus B19 infection. Clin Rheumatol. 2002 Aug:21(4):306-8.

39. Lowry SM, Brent LH, Menaldino S, Kerr JR. A case of persistent parvovirus B19 infection with bilateral cartilaginous and ligamentous damage to the wrists. Clin Infect Dis Off Publ Infect Dis Soc Am. 2005 Aug 15;41 (4):e42-4.

40. Mogensen TH, Jensen JMB, Hamilton-Dutoit S, Larsen CS. Chronic hepatitis caused by persistent parvovirus B19 infection. BMC Infect Dis. 2010;10:246.

41. Munakata Y, Kodera T, Saito T, Sasaki T. Rheumatoid arthritis, type 1 diabetes, and graves' disease after acute parvovirus B19 infection. Lancet. 2005 Sep 27;366(9487):780

42. Pironi L, Bonvicini F, Gionchetti P, D'Errico A, Rizzello F, Corsini C, et al. Parvovirus b19 infection localized in the intestinal mucosa and associated with severe inflammatory bowel disease. J Clin Microbiol. 2009 May;47(5):1591-5.

43. Stahl HD, Pfeiffer R, Emmrich F. Intravenous treatment with immunoglobulins may improve chronic undifferentiated mono- and oligoarthritis. Clin Exp Rheumatol. 2000 Aug;18(4):515-7.

44. Bonvicini F, Bua G, Manaresi E, Gallinella G. Antiviral effect of cidofovir on parvovirus B19 replication. Antivir Res. 2015 Jan;113:11-8.

45. Chiche L, Grados A, Harlé J-R, Cacoub P. Mixed cryoglobulinemia: a role for parvovirus b19 infection. Clin Infect Dis Off Publ Infect Dis Soc Am. 2010 Apr 1;50(7):1074-5

\section{Ready to submit your research? Choose BMC and benefit from:}

- fast, convenient online submission

- thorough peer review by experienced researchers in your field

- rapid publication on acceptance

- support for research data, including large and complex data types

- gold Open Access which fosters wider collaboration and increased citations

- maximum visibility for your research: over $100 \mathrm{M}$ website views per year

At BMC, research is always in progress.

Learn more biomedcentral.com/submissions 